\title{
Tratamento cirúrgico do abscesso aórtico com descontinuidade ventrículo esquerdo-aorta em endocardite infecciosa
}

\author{
Antoninho Sanfins ARNONI*, Hélio Carlos Brandão FALCÃO, João Bosco de OLIVEIRA**, Jarbas J. DINKHUY- \\ SEN $^{*}$, Camilo ABDULMASSIH NETO*, Paulo CHACCUR ${ }^{\star \star \star}$, Adib D. JATENE ${ }^{\star \star \star}$, Luiz Carlos Bento de \\ SOUZA*, Paulo P. PAULISTA*
}

\begin{abstract}
ARNONI, A. S.; FALCĀO, H. C. B.; OLIVEIRA, J. B.; DINKHUYSEN, J. J.; ABDULMASSIH NETO, C.; CHACCUR, P.; JATENE, A. D.; SOUZA, L. C. B.; PAULISTA, P. P. - Tratamento cirúrgico do abcesso aórtico com descontinuidade ventrículo esquerdo-aorta em endocardite infecciosa. Rev. Bras. Cir. Cardiovasc., 2(1):53-60, 1987

RESUMO: A endocardite infecciosa é uma complicação séria, em pacientes portadores de valvopatias, e, algumas vezes, apresenta dificuldades técnicas para sua correçāo. Uma dessas situaçōes diz respeito a disfunçōes de próteses colocadas em posição aórtica, ou de valvas naturais aórticas, em que a endocardite leva à descontinuidade entre o ventrículo esquerdo e a aorta, por comprometimento da continuidade mitroaórtica, ou do septo muscular. No Instituto Dante Pazzanese de Cardiologia, operamos 3 pacientes, nos quais havia abscesso em fundo cego, mas provocando grande separação entre o ventrículo esquerdo e a aorta e nos quais a fixação da prótese não poderia ser feita pelas técnicas habituais, nem pela suspensão do folheto anterior da mitral. Nesses casos, reconstruímos a continuidade entre o ventrículo esquerdo e a aorta, empregando retalho de pericárdio bovino e fixando a prótese, em parte, no anel valvar ainda preservado e, em parte, em um anel criado pelos pontos passados no pericárdio implantado. Um desses pacientes faleceu com 26 dias de pós-operatório, por embolia pulmonar, e com a prótese normal. Os 2 outros receberam alta e estão assintomáticos, com 14 e 4 meses de evolução. $O$ último tem discreto refluxo aórtico, ao ecocardiograma.
\end{abstract}

DESCRITORES: abscesso aórtico, cirurgia; endocardite infecciosa.

\section{INTRODUÇĀO}

Antes da era dos antibióticos, a endocardite era uma doença fatal ${ }^{13}$. O tratamento precocē com antibióticos aumentou a sobrevida, mas não foi suficiente para baixar os indices de mortalidade a níveis satisfatórios. A intervenção cirúrgica, também precoce em alguns casos, tem sido importante para a melhoria dos resultados, evitando que o paciente possa chegar a insuficiência cardiaca congestiva, ou a septicemia incontrolável, ou que ainda apresente episódios graves de embolização.

WALLACE et alii ${ }^{24}$, em 1965, já preconizavam a substituição da valva em portadores de endocardite, como uma forma de diminuir a mortalidade. Vários autores começaram a empregar esta atitude, e a sobrevida dos pacientes veio aumentando.

Trabalho realizado no Instituto Dante Pazzanese de Cardiologia, São Paulo, SP, Brasil.

Apresentado ao 14: Congresso Nacional de Cirurgia Cardiaca. Salvador, BA, 27 e 28 de março, 1987.

- Do Instituto Dante Pazzanese de Cardiologia.

* Do Serviço de Clínica e Cirurgia Cardiovascular Prof. Dr. Adib Jatene. Hospital São Joaquim da Beneficência Portuguesa.

... Do Hospital do Coração da Associação do Sanatório Sírio.

Endereço para separatas: Antoninho S. Arnoni. Caixa Postal 215, São Paulo, SP. Brasil. 
ARNONI, A. S.; FALCĀO, H. C. B.; OLIVEIRA, J. B.: DINKHUYSEN, J. J.: ABDULMASSIH NETO, C.; CHACCUR, P.; JATENE, A. D.; SOUZA, L. C. B.; PAULISTA, P. P. - Tratamento cirúrgico do abscesso aórtico com descontinuidade ventrículo esquerdo-aorta em endocardite infecciosa. Rev. Bras. Cir. Cardiovasc., 2(1):53-60, 1987.

Entretanto, a incidência da endocardite infecciosa continua elevada e para isso têm contribuído o abuso da ingestão de drogas, a má condição dentária dos pacientes, o uso cada vez maior de cateterismos venosos ${ }^{14} \mathrm{e}$, também, a crescente populaçāo de portadores de próteses artificiais. Se associarmos $\mathrm{a}$ isto $\mathrm{o}$ aparecimento de formas mais virulentas de endocardite, como as estafilocócicas, ou fúngicas, veremos a necessidade de investigação rigorosa e intervenção precoce, neste grupo de pacientes, se quisermos obter melhores resultados $^{6}$.

Mas essa incidência de organismos mais virulentos tem-nos levado a situaçōes de difícil correção cirúrgica, quer em portadores de próteses artificiais, quer em valvas naturais. O comprometimento dos folhetos, com preservação do anel de implantação, ou o comprometimento apenas da prótese, tem resolução que merece bastante cuidado, mas que pode ser sanado sem grandes complicações.

Entretanto, quando a raiz da aorta, o anel valvar, ou a continuidade ventrículo esquerdo-aorta estão incluídos no processo, a resolução torna-se problemática e várias técnicas têm sido tentadas, na sua correção.

No Instituto Dante Pazzanese de Cardiologia, tivemos oportunidade de levar à cirurgia 3 pacientes que apresentavam descontinuidade ventrículo esquerdo-aorta, com formação de grandes abscessos e cuja correção cirúrgica discutiremos neste trabalho.

\section{CASUÍSTICA}

Caso 1 - Paciente de 35 anos, operado em 1977, para colocação de prótese de dura-máter em posição aórtica por estenose aórtica de origem reumática. Fez ecocardiograma em 1983, mostrando prótese sem sinais de disfunção. Retornou ao hospital em agosto de 1985, queixando-se de que, há 2 meses, vinha apresentando anorexia, emagrecimento e mal-estar. O ecocardiograma mostrou vegetações na prótese aórtica. Como não obtivesse melhora com o tratamento instituído, foi indicada cirurgia. A reoperação foi realizada no dia 30.08 .85 e, na ocasião, notou-se abscesso grande, que só deixava livre a região infra-seio coronário direito. A correção foi feita passando-se pontos ancorados em barra de Teflon, procurando reaproximar $o$ anel mitral do aórtico. Implantamos prótese tipo StarrEdwards 11A. O paciente evoluiu bem e recebeu alta com 20 dias de pós-operatório. No dia 05.11.85 procurou o hospital com quadro de anemia hemolítica importante, por provável trauma mecânico. Foi submetido a exames e o ecocardiograma revelou vazamento perivalvar. O estudo hemodinâmico mostrou insuficiência aórtica importante, com pressões normais em cavidades direitas. Tinha, na ocasião, DHL de 3263 e reticulócitos de $9,5 \%$. O hematócrito era de $31 \%$. Foi novamente operado, no dia 22.11.85 e apresentava vazamento perivalvar severo, com a prótese praticamente solta e nova formação de abscesso abaixo da prótese. A cultura da prótese revelou Bacillus sp.

Caso 2 - Paciente com 40 anos de idade, masculino, que procurou o hospital procedente de outro Estado, onde fora submetido, em junho de 1986 , a substituição de valva aórtica associada a fechamento de comunicação interventricular, na vigência de endocardite provocada por Pseudomonas, segundo relatório que nos foi encaminhado. $\mathrm{Na}$ ocasião, foi colocada prótese biológica de porco e a comunicação interventricular, fechada com pontos ancorados em forma de $U$, que também foram usados para fixar a prótese. Teve alta em julho, mas, no mês seguinte, foi reinternado e, apesar da utilização de vários esquemas antibióticos, agravou o quadro e, no dia 16.08 .86 foi encaminhado a nosso Serviço. Ao exame, mostrava palidez intensa e fígado e baço aumentados de tamanho. $O$ ecocardiograma não mostrou vegetaçōes. Apesar dos esquemas antibióticos. não tinha melhora do estado geral. Novo ecocardiograma, em 03.09.86, mostrou vegetações na prótese e suspeita de vegetações em valva pulmonar. Foi reoperado no dia 05.09.86 e apresentava vazamento perivalvar no local correspondente ao seio não coronário, com vegetação na bioprótese. O local onde foi suturada a comunicação interventricular estava íntegro. Retirada a prótese, visualizava-se grande abscesso comprometendo a continuidade entre o ventrículo esquerdo e a aorta. À exploração da valva pulmonar, encontramos pequena vegetação entre os dois folhetos posteriores. O exame anátomo-patológico mostrou prótese valvular biológica intensamente autolizada, com endocardite, e a cultura revelou Mycobacterium chelonei.

Caso 3 - Paciente de 27 anos de idade, masculino, que deu entrada no hospital em 16.10.86, revelando que, após extração dentária realizada 45 dias antes, começou a apresentar adinamia, anorexia e dispnéia aos grandes esforços, que evoluiu e, no momento, estava aos mínimos esforços. O ecocardiograma mostrou valva aórtica bicúspide com insuficiência importante e vegetações, além de provável abscesso do seio de Valsalva. A cirurgia 
ARNONI, A. S.; FALCÃO, H. C. B.; OLIVEIRA, J. B.; DINKHUYSEN, J. J.; ABDULMASSIH NETO, C.; CHACCUR, P.; JATENE, A. D.: SOUZA, L. C. B.: PAULISTA, P. P. - Tratamento cirúrgico do abscesso aórtico com descontinuidade ventrículo esquerdo-aorta em endocardite infecciosa. Rev. Bras. Cir. Cardiovasc., 2(1):53-60, 1987.

foi realizada no mesmo dia. A valva aórtica era bicúspide e estava totalmente destruída por endocardite. Retirada a valva, havia grande abscesso comprometendo toda a porção fibrosa da junta entre o ventrículo esquerdo e a aorta. A cultura da prótese revelou Streptococcus viridans.

\section{TÉCNICA OPERATÓRIA}

A cirurgia foi realizada através de toracotomia mediana transesternal. $O$ pericárdio, quando aderido, e o estava nos dois casos de reoperação, foi liberado sem acidentes. A circulação extracorpórea foi instalada utilizando-se as duas veias cavas e a artéria femoral nas reoperaçōes. No caso de primeira cirurgia, utilizamos a aorta ascendente, que é a rotina no Serviço. O oxigenador utilizado foi o de bolhas, descartável, modelo Jatene-Macchi IC-1000. O perfusato dependeu das condições prévias do paciente e a hemodiluição foi empregada sempre que possível. A temperatura foi baixada para $29^{\circ} \mathrm{C}$. Utilizamos, nos três casos, parada cardioplégica com canulação seletiva dos óstios coronários e solução com $30 \mathrm{mEq} / 1$ de cloreto de potássio a $19,1 \%$ e $2 \mathrm{ml}$ de bicarbonato de sódio a $10 \%$ e $500 \mathrm{ml}$ de glicose a $5 \%$. A cardioplegia era repetida a cada 40 minutos e o pericárdio era freqüentemente irrigado com soro gelado, para manter fria a temperatura do miocárdio. O tempo médio de clampeamento da aorta foi de 123 minutos (115, 145 e 110).

Após a cardioplegia, inspecionamos as próteses, nos dois casos de reoperação, e a valva, no caso de primeira cirurgia. As próteses apresentavam vazamento perivalvular severo. No primeiro caso, havia comunicação que abrangia toda a região correspondente ao seio não coronário. No segundo, a prótese biológica estava íntegra, com foIhetos amarelados, com vegetação e havia vazamento perivalvular que correspondia a $1 / 5$ do anel valvar. No terceiro, a valva era bicúspide e estava toda destruída por endocardite. Retiradas as próteses ou a valva, havia grande abscesso com erosão do anel, que sempre abrangia todo o seio não coronário e, em grau variado, o coronário esquerdo e o coronário direito. $\mathrm{O}$ folheto anterior da mitral, nos 3 casos, estava desabado, com grande distância do que seria o anel aórtico, formando uma cavidade em fundo cego, com material necrótico no seu interior. Nos 3 casos, o septo membranoso também estava comprometido em grau variado e, no terceiro paciente, a cavidade ia desde a metade do seio coronário esquerdo, ocupava toda região infra-seio não coronário e ia até a metade do coro- nário direito. Realizamos limpeza e retirada de todo o tecido necrótico, com cuidado para que nenhum fragmento atingisse os óstios coronários, e lavamos a cavidade ventricular com soro gelado.

Em seguida, reconstruímos a continuidade ventrículo esquerdo-aorta, utilizando pontos separados em $U$ de polipropileno 4-0 passados no folheto anterior da mitral, na parte fibrosada do septo membranoso, subindo em direção à aorta, e, após, na raíz da aorta onde o tecido fosse menos friável. Tais pontos foram, depois, passados em retalho duplo de pericárdio bovino conservado em glutaraldeído, com formato que dependeu da extensão do abscesso. No terceiro caso, chegamos a usar 23 fios na reconstrução da continuidade entre o ventrículo esquerdo e a aorta.

Reconstruída a continuidade, passamos pontos de poliéster 2-0 ancorados em almofadas de Teflon no restante do anel aórtico e no retalho de pericárdio bovino, criando um neo anel nessa região. Nos 2 primeiros casos, a região com pericárdio correspondeu à metade da circunferência total do anel e, no terceiro, chegou a $2 / 3$ do anel. Em todos os casos, utilizamos a prótese de StarrEdwards (11A, 15A, 11A).

No segundo paciente, exploramos a valva pulmonar, que mostrava pequena vegetação entre dois folhetos e que foi tratada com retirada e limpeza da área.

Os 3 pacientes saíram de extracorpórea com ritmo sinusal, mantendo condições hemodinâmicas estáveis.

\section{RESULTADOS}

Dois dos pacientes evoluíram com sangramento aumentado no pós-operatório imediato, tendo um deles sido reoperado por sangramento na linha de sutura da aortotomia e outro, apresentado hemitórax à direita, que foi drenado.

Passado o período de internação na Unidade de Terapia Intensiva, a evolução foi satisfatória, em 2 casos, sem grandes intercorrências, fazendo uso de antibioticoterapia, que dependeu dos exames realizados.

O segundo paciente, com 26 dias de pós-operatório, apresentou quadro sugestivo de embolia pulmonar, vindo a falecer no mesmo dia. Até então, manteve-se com ausculta da prótese normal e com condições hemodinâmicas estáveis. A cultura tinha 
ARNONI, A. S.; FALCĀO, H. C. B.; OLIVEIRA, J. B.; DINKHUYSEN. J. J.; ABDULMASSIH NETO, C.; CHACCUR, P.; JATENE, A. D.: SOUZA, L. C. B.: PAULISTA, P. P. - Tratamento cirúrgico do abscesso aórtico com descontinuidade ventrículo esquerdo-aorta em endocardite infecciosa. Rev. Bras. Cir. Cardiovasc., 2(1):53-60, 1987.

revelado Mycobacterium chelonei e a medicação específica foi empregada; entretanto, o quadro geral já vinha piorando, nos últimos dias.

Os outros 2 pacientes receberam alta hospitalar e estão, no momento, assintomáticos e exercendo suas funções normalmente. O primeiro está com 14 meses de evolução, sem sinais de disfunção, ou vazamento perivalvular e com a anemia hemolítica do pré-operatório resolvida. Apresentou, na evolução, um episódio de fibrilação atrial, revertida com uso de medicação.

O outro paciente, com 4 meses de pós-operatório, apresenta discreto vazamento perivalvular, ao ecocardiograma, mas sem repercussão hemodinâmica.

\section{COMENTÁRIOS}

A endocardite infecciosa é uma complicação séria, em valvopatas, quer em sua valva natural, quer em portadores de próteses artificiais.

A evolução da cirurgia cardíaca levou a melhoria crescente, nas próteses artificiais ${ }^{16,19}, \mathrm{com}$ modificações. que procuram diminuir os riscos das complicações que sua presença no coração possa acarretar. $O$ desenho das válvulas parece não influir na incidência da endocardite, mas um controle adequado na sua confecção e um controle rigoroso do próprio paciente podem baixar esse risco.

A virulência do organismo causador da endocardite é importante, pois determina a evolução da doença e pode nos obrigar a atitudes mais agressivas com maior brevidade. Sabe-se que os estreptococos são os agentes mais encontrados nas endocardites e que uma antibioticoterapia adequada pode nos levar a ter sucesso no seu tratamento. Já agentes mais virulentos, como os estafilococos, principalmente o Stafilococcus aureus, ou fungos, nos obrigam a uma indicação cirúrgica precoce, para evitar que as condiçōes do paciente deteriorem, ou que o acometimento do aparelho valvar seja mais severo, com dificuldades para sua correção.

A indicação cirúrgica para portadores de endocardite em fase aguda já está bem definida. ASLIP et alii ${ }^{2}$ consideram, como indicaçōes para cirurgia de emergência, o comprometimento hemodinâmico, quer por insuficiência cardíaca severa, ou por obstrução valvar, a infecção não controlada, principalmente na endocardite fúngica, nas bacteremias persistentes, ou quando não há agente antimicrobiano efetivo e, finalmente, em portadores de próteses. O mesmo autor relata, como indicaçōes relativas à etiologia não estreptocócica, as embolias de repetição (duas ou mais), a evidência de extensão intracardiaca, a presença de vegetaçōes ao ecocardiograma, o vazamento perivalvular em portadores de prótese e a reincidência da doença.

Em nosso meio ${ }^{10}$, a cirurgia tem sido indicada de urgência na presença de insuficiência cardiaca congestiva, de tromboembolismo, ou toxemia persistente. Ultimamente e acompanhando o que vários autores vêm admitindo ${ }^{4}$, temos indicado cirurgia mais precocemente, nos portadores de endocardite por Stafilococcus aureus.

A correção cirúrgica, apesar da mortalidade relativamente alta, quando comparada às cirurgias valvares sem complicaçōes ${ }^{4,8}, 10,17$, devido à gravidade das situações clínicas em que o paciente chega ao centro cirúrgico, pode não apresentar maiores dificuldades técnicas, principalmente se o anel valvar não estiver comprometido.

Entretanto, quando há acometimento da raíz da aorta, do anel valvar, ou quando há destruição da continuidade ventrículo esquerdo-aorta, com formação de abscessos, as dificuldades podem ser grandes e a mortalidade operatória tende a se elevar.

A primeira discussão que surge, nos casos de pacientes portadores de abscessos do anel valvar, é o próprio termo "abscesso". UTLEY \& MILLS ${ }^{22}$ preferem chamá-los de erosão do anel, já que, segundo eles, abscesso não seria um bom termo, porque estão em comunicação com a luz da aorta, não contêm material purulento e, freqüentemente, são estéreis devido à terapêutica antibiótica. Desta forma, eles seriam mais importantes pelo problema hemodinâmico que causam e não como fonte de infecção residual. Acreditam, também, que os abscessos são mais encontrados em portadores de Stafilococcus aureus que de estreptococos e que o Stafilococcus aureus seria o agente mais encontrado nos abscessos. A erosão é mais freqüente em portadores de próteses artificiais e nas valvas naturais, mais freqüente em congênitos do que em reumáticos. Nos 3 casos de nossa série, 2 tinham próteses prévias e o terceiro apresentava valva aórtica bicúspide não reumática.

ARNETT \& ROBERTS ${ }^{1}$, analisando 95 casos de necrópsia, apresentam cinco fatores que podem nos levar a pensar em abscesso na presença de endocardite: a) envolvimento da valva aórtica; b) 
ARNONI, A. S.: FALCĀO, H. C. B.: OLIVEIRA, J. B.; DINKHUYSEN, J. J.; ABDULMASSIH NETO, C.: CHACCUR, P.: JATENE, A. D.: SOUZA, L. C. B.: PAULISTA, P. P. - Tratamento cirúrgico do abscesso aórtico com descontinuidade ventriculo esquerdo-aorta em endocardite infecciosa. Rev. Bras. Cir. Cardiovasc., 2(1):53-60, 1987

presença de regurgitação valvar recente; c) evidência de pericardite; d) alto grau de bloqueio átrio-ventricular e e) pequena duração dos sintomas, levando a grande debilidade.

A correção cirúrgica vai depender do grau de acometimento do anel valvar, da continuidade ventrículo esquerdo-aorta e da localização do abscesso. Assim, conforme a localização, poderíamos ter a formação de comunicações interventriculares, ou bloqueios por lesões no tecido de condução no septo muscular, ou destruição da continuidade mitroaórtica, podendo, até, chegar ao comprometimento da valva mitral, ou, ainda, destruição do septo membranoso.

Várias técnicas têm sido indicadas para corrigir esses problemas, desde a substituição valvar com reforço de almofadas de Teflon para fechar o abscesso, até a colocação de tubos valvulados com reimplante de coronárias, ou com modificações na posição da prótese e realização de pontes de veia safena.

A técnica mais habitual, e que parece a primeira opção quando o abscesso não é grande, é a refixação do anel com emprego de pontos em $\mathrm{U}$ ancorados, ou em almofadas de Teflon, ou mesmo em uma barra de Teflon, levantando o folheto anterior da mitral, ou o septo, para a posição do anel valvar, e fixando aí uma nova prótese. Esta foi a técnica que também usamos, sempre que possível, e que empregamos no primeiro caso, quando da substituição de sua prótese biológica por metálica. Como voltasse a ter problemas, na reintervenção, utilizamos a técnica que agora descrevemos.

BUCKLEY et alii ${ }^{5}$ descrevem 15 casos de pacientes com complicações envolvendo a raíz da aorta, a valva aórtica e a aorta ascendente e, em 1 deles, havia comprometimento do septo muscular e, em 2, do folheto anterior da mitral. Usaram, sempre, pontos ancorados em almofadas de Teflon para corrigir o problema e implantar uma prótese de Starr-Edwards.

HATCHER et alii ${ }^{12}$ relatam 2 casos de envolvimento do anel e da aorta ascendente, nos quais trocou as valvas e reconstruiu a aorta ascendente com enxerto de Teflon, preservando os óstios coronários direito e esquerdo. Um dos pacientes faleceu por rotura da linha de sutura aórtica, devido a infecção causada pelo mesmo agente que a cultura de sangue houvera demonstrado.

SYMBAS et alii ${ }^{21}$ descrevem 5 casos, com substituição valvar, nos quais usaram, técnica que dependeu da localização e do tamanho do abscesso. Em 2 casos de pequeno abscesso, usaram a técnica de pontos ancorados em almofadas de Teflon para fechar o abscesso e fixar a prótese, usando pontos separados no restante do anel, onde não havia alterações. No terceiro caso, em que o abscesso era maior, inclusive destruindo parte do tecido fibroso da continuidade mitroaórtica, usaram técnica semelhante, mas tiveram que reoperar o paciente quarenta e oito dias depois, e usaram um retalho de Dacron em forma de trapézio, fixado no septo muscular e na parede da aorta, preservando os óstios coronários. No quarto caso, já usaram diretamente a técnica do retalho trapezoidal, mas em posição um pouco diferente, pois envolvia o seio não coronário. O paciente apresentou, no pós-operatório, vazamento perivalvular discreto. No último caso, com envolvimento maior e grande descontinuidade ventrículo-aorta, usaram grande retalho de Dacron de forma retangular, envolvendo parte do septo membranoso e quase todo o septo muscular. Fizeram sutura com pontos separados na aorta, devido à proximidade dos óstios coronários. A prótese foi implantada parte no anel nativo e parte no retalho.

BAILEY et alii ${ }^{3}$ relatam 6 casos, nos quais usaram retalho de Dacron, para fechamento do aneurisma e implantaram a prótese em parte, nesse retalho. Houve uma comunicação interventricular, no pós-operatório, por soltura de pontos no retalho.

OLINGER \& MALONEY ${ }^{15}$ usam técnica semeIhante à de Buckley, mas empregando uma esponja de feltro de Dacron como suporte.

DANIELSON et alii ${ }^{7}$, em 1974, apresentam um caso de paciente operado que se assemelha ao primeiro caso que descrevemos, mas com correção cirúrgica diferente. $O$ paciente, quando da primeira cirurgia, apresentava abscesso abaixo do óstio da coronária esquerda e dois pequenos abscessos no seio não coronário. A correção foi a reaproximação do folheto anterior da mitral com pontos separados ancorados em Teflon. No 5: dia de pós-operatório, começou a apresentar sopro, que foi aumentando de intensidade, ievancio a cirurgia de emergência, no 13: dia. A correção consistiu na retirada da prótese, limpeza do abscesso, colocação de uma prótese na metade da aorta ascendente, fechamento dos óstios coronários e realização de pontes de veia safena para a descendente anterior e a coronária direita.

Algumas críticas podem ser feitas a este método, mas ele tem sido empregado por outros autores, 
ARNONI, A. S.; FALCÃO, H. C. B: OLIVEIRA, J. B.; DINKHUYSEN, J. J.; ABDULMASSIH NETO, C.: CHACCUR, P.; JATENE. A. D.; SOUZA, L. C. B.; PAULISTA, P. P. - Tratamento cirúrgico do abscesso aórtico com descontinuidade ventriculo esquerdo-aorta em endocardite infecciosa. Rev. Bras. Cir. Cardiovasc., 2(1):53-60, 1987.

na sua descrição original, ou com modificações técnicas.

REITZ et alii ${ }^{18}$ publicaram 4 casos com emprego de tubo valvulado na aorta ascendente, fechamento dos óstios coronários e realização de pontes de veia safena, que variaram de caso para caso. Utilizam esta técnica somente quando a quase totalidade da circunferência do anel está necrosada.

FRANTZ et alii' também empregam tubo valvulado para correção de grandes abscessos, mas, nos 2 casos de sua série, fizeram reimplante das artérias coronárias no tubo. O tubo é implantado no anel aórtico remanescente, na musculatura ventricular e na base do folheto anterior da valva mitral.

A mesma técnica foi usada por Van HOOSER et alii ${ }^{23}$, em 4 casos de sua experiência. Tiveram uma reoperação, por sangramento e baixo débito, que necessitou balão intra-aórtico, além de dois óbitos tardios, um por recidiva da endocardite e outro por síndrome de imunodeficiência adquirida em um toxicômano.

RUMISEK et alii ${ }^{20}$ descrevem uma variante para implante do tubo valvulado e reimplante das coronárias, abrindo o infundíbulo do ventrículo direito e passando pontos pelo septo para dar maior segurança e fixação.

DONALDSON \& ROSS $^{9}$ preferem usar homoenxerto com reimplante das artérias coronárias. Apresentam uma série de 10 pacientes, com dois óbitos imediatos e duas complicações na evolução tardia, uma disfunção valvar e uma fístula entre o ventrículo esquerdo e a artéria pulmonar, além da disfunção da valva.

Os pacientes operados em nossa Instituição apresentavam grandes abscessos, comprometendo, principalmente, a parte fibrosa de continuidade ventrículo esquerdo-aorta. Isto nos permitiu utilizar o pericárdio bovino para reconstruir essa continuidade e, para isto, usamos pontos separados fixados no folheto anterior da valva mitral, na parte no septo membranoso e, depois, na aorta ascendente. O tamanho e o formato do retalho variaram, em cada caso, dependendo da extensão do abscesso. Em 1 dos casos, só pudemos utilizar $1 / 3$ do anel nativo para implantar a prótese, já que o abscesso ia desde o meio do seio coronário esquerdo, comprometia todo o não coronário e ia até a metade do coronário direito, envolvendo valva mitral, septo membranoso e parte do septo muscular. Os pontos para fixação da prótese foram passados nas partes possíveis do anel aórtico preservado e, após, no pericárdio, formando um neo anel nessa região.
Críticas podem ser feitas a cada um desses métodos de correção. Assim, a técnica de fixação com pontos ancorados em Teflon, usada para fechar o abscesso e fixar a prótese, só deve ser empregada em abscessos pequenos. Nos maiores, a tensão pode levar, no futuro, a um vazamento perivalvular e à necessidade de nova operação.

A colocação de prótese na aorta ascendente, com ponte de veia safena, pode sofrer duas considerações. Uma, a própria necessidade de pontes de veia safena, principalmente em pacientes jovens, e a outra, a de que o abscesso fica submetido à pressão do ventrículo esquerdo e pode se expandir, ou, até mesmo, romper-se.

O emprego de tubo valvulado com reimplante de artérias coronárias é questionado por muitos, devido à dificuldade técnica do implante do tubo no ventrículo esquerdo e pela própria dificuldade de reimplantar os óstios coronários. A mesma observação é feita pelos críticos do emprego do homoenxerto.

Quando da presença de abscesso no anel aórtico, todas as outras valvas podem estar envolvidas e há referências ao comprometimento da valva tricúspide $^{5}$, com destruição do folheto septal, que levou a grande infiltrado pulmonar.

Um dos nossos pacientes apresentava pequena vegetação em valva pulmonar, que, apesar de retirada no ato cirúrgico, pode ter contribuído para a evolução do paciente, que veio a falecer por embolia pulmonar.

Em conclusão, acreditamos que a melhoria das técnicas de proteção miocárdica, a própria evolução da cirurgia, dos oxigenadores e dos controles pós-operatórios nos autorizam a ter uma atitude agressiva mais precoce, nos portadores de endocardite, principalmente naqueles com próteses e nos em que o agente seja estafilococos, ou fungos. A espera pode levar à mesa cirúrgica pacientes com péssimas condições clínicas, ou com destruições de estruturas intracardíacas, tornando 0 ato cirúrgico mais difícil e apresentando piores resultados.

A técnica que descrevemos com o uso de pericárdio bovino é uma alternativa para os pacientes com destruição da continuidade entre o ventrículo esquerdo e a aorta, por abscesso, pelo não emprego de tubos de Dacron e por se tornarem desnecessários a realização de pontes de veia safena, ou o reimplante de artérias coronárias. O pericárdio bovino já tem sido usado em várias correçōes de defeitos intracardíacos e a facilidade no seu manu- 
ARNONI, A. S.; FALCÃO, H. C. B.; OLIVEIRA, J. B.; DINKHUYSEN, J. J.; ABDULMASSIH NETO, C.; CHACCUR, P.; JATENE. A. D.; SOUZA, L. C. B.; PAULISTA, P. P. - Tratamento cirúrgico do abscesso aórtico com descontinuidade ventriculo esquerdo-aorta em endocardite infecciosa. Rev. Bras. Cir. Cardiovasc., 2(1):53-60, 1987.

seio auxilia na realização da técnica. Ela não pode ser empregada em todos os casos, principalmente se houver comprometimento dos óstios coronários, mas é uma possibilidade que deve ser pensada, sempre que a endocardite provocar destruição do anel aórtico, com descontinuidade entre o ventrículo esquerdo e a aorta, e que a sutura direta ficar sob tensão, ou em tecido friável, e que possam, no futuro, levar a vazamentos perivalvulares importantes.

RBCCV

ARNONI, A. S.; FALCĀO, H. C. B.; OLIVEIRA, J. B.; DINKHUYSEN, J. J., ABDULMASSIH NETO, C.; CHACCUR, P.; JATENE, A. D.; SOUZA. L. C. B.; PAULISTA, P. P. - Surgical treatment of aortic abscess in infectious endocarditis. Rev. Bras. Cir. Cardiovasc., 2(1):53-60, 1987

ABSTRACT: Infectious endocarditis is a serious complication in patients with valve diseases and sometimes presents technical difficulties for its treatment. One of those situations concerns prosthesis dysfunctions placed in aortic position or of natural aortic valves, in which endocarditis causes partial descontinuity between the left ventricle and the aorta by the lesion of the continuity of the mitral-aortic or of the muscular septum. In the Instituto Dante Pazzanese de Cardiologia we operated three patients with closed abscesses but with a great separation between the left ventricle and the aorta in which the fixation of the prosthesis couldn't be done by the usual technique nor by the suspension of the anterior mitral leaflet. We reestablished continuity between the left ventricle and the aorta using a patch of bovine paricardium and attaching part of the prosthesis to the preserved valvar ring and the other part in a ring created by the mattress sutures passed in the implanted pericardium. One patient died with 26 days post-surgery due to pulmonary emboly. The other two were discharged and are without symptoms at 14 and 4 months of evolution. The last one has a slight aortic reflux.

DESCRIPTORS: aortic abscess, surgery; endocarditis, infectious.

\section{REFERÊNCIAS BIBLIOGRÁFICAS}

1 ARNETT, E. N. \& ROBERTS, W. C. - Valve ring abscess in active infective endocardites. Circulation, 54 (1): 140-145, 1976

2. ASLIP, S. G.; BLACKSTONE, E. H.; KIRKLIN, J. W.; COBBS, C. G. - Indications for cardiac surgery in patients with active infective endocardites. $A m$. J. Med., 78 (Supl. 6B); 138-148, 1985.

3. BAILEY, W. W.; IVEY, T. D.; MILLER, D. W. - Dacron patch closure of aortic annulus mycotic aneurysms. Circulation, 66 (Supl. 1): 127-129, 1982.

4. BOYD, A. D.; SPENCER, F. C.; ISOM, O. W.; CUNNINGHAM, J. N.; REED, G. E.; ACINAPURA, A. J.; TICE, D. A. - Infective endocarditis: an analysis of 54 surgically treated patients. J. Thorac. Cardiovasc. Surg., 73 (1): 23-29, 1977.

5. BUCKLEY, M. J.; MUNDTH, E. D.; DAGGETT, W. M.; AUSTEN, G. - Surgical management of the complications of sepsis, involving the aortic valve, aortic root and ascending aorta. Ann. Thorac. Surg., 12 (4) 391-399, 1971.

6. CUKINGNAN, R. A.; CAREY, J. S.; WITTING, J. H.; CIMOCHOWSKY, G. E. - Early replacement in active infective endocarditis. J. Thorac. Cardiovasc. Surg., 85 (2): 163-173, 1983.
7. DANiELSON, G. K.; TITUS, J. L.; DUShANE, J. W. Sucessful treatment of aortic valve endocarditis and aortic root abscess by insertion of prosthetic valve in ascending aorta and placement of bypass grafts to coronary arteries. J. Thorac. Cardiovasc. Surg., 67 (3) 443-449, 1974.

8. DIAS, A. R.; GRINBERG, M.; MANSUR, A.; POMERANTZEFF, P. M. A.; VERGINELLI, G.; ZERBINI, E. J.; JATENE, A. D. - Avaliação dos resultados do tratamento cirúrgico da endocardite i fecciosa na fase ativa da doença. Arq. Bras. Cardiol., 47 (4): 275-278, 1986.

9. DONALDSON, R. M. \& ROSS, D. M. - Homograft aortic root replacement for complicated prosthetic valve endocarditis. Circulation, 70 (Supl. 1): 178-181, 1984.

10. FALUDI, A. A.; ASSEF, J. E.; BATLOUNI, M.; GUTPARAKIS, V. L. M.; STORTI, C. - Tratamento cirúrgico na fase aguda da endocardite infecciosa. Arq. Bras. Cardiol., 44 (2): 93-96, 1985.

11. FRANTZ, P. T.; MURRAY, G. F.; WILCOX, B. R. - Surgical management of left ventricular-aortic descontinuity complicating bacterial endocarditis. Ann. Thorac. Surg., 29 (1): 1-7, 1980.

12. HATCHER, C. R.; SYMBAS, P. N.; LOGAN, W. D.; MANSOUR, K. A.; ABBOTT, O. A. - Surgical management of complications of bacterial endocarditis. Ann. Surg., 173 (6): 1045-1052, 1971. 
ARNONI, A. S.: FALCÃO, H. C. B.; OLIVEIRA, J. B.; DINKHUYSEN. J. J.; ABDULMASSIH NETO, C.; CHACCUR, P.: JATENE, A. D.: SOUZA, L. C. B.; PAULISTA, P. P. - Tratamento cirúrgico do abscesso aórtico com descontinuidade ventriculo esquerdo-aorta em endocardite infecciosa. Rev. Bras. Cir. Cardiovasc., 2(1):53-60, 1987.

13. LERNER, P. L. \& WEINSTEIN, L. - Infective endocarditis in antibiotic era. N. Eng. J. Med., 274 (5): 259-266, 1966.

14. LOIRE, R.; MADONNA, O.; TABIB, A. - Les abcès cardiaques dans l'endocardite infectieuse. Arch. Mal. Coeur, 8 (5): 1216-1222, 1985

15. OLINGER, G. \& MALONEY, J. V. - Repair of left ventricular-aortic discontinuity complicating endocarditis from aortic valve prosthesis. Ann. Thorac. Surg., 23 (6): 576-577, 1977.

16. PATON, B. \& VOGEL, J. H. K. - Valve replacement: the first quarter century, J. Am. Coll. Cardiol., 6 (4): $897-898,1985$.

17. RABELO, R. C.; SOUZA, L. S. S.; MARINO, R. L.; MARINO, M. A.; RABELO, W.; BERNARDES, R. C.; STEHLING, A. P.; CAMPOS, J. B. - Tratamento cirúrgico da endocardite infecciosa na fase de estado da doença. Arq. Bras. Cardiol., 39 (4): 235-239, 1982.

18. REITZ, B. A.; STINSON, E. B.; WATSON, D. C.; BAUMGARTNER, W. A.; JAMIESON, S. W. - Translocation of the aortic valve for prosthetic valve endocarditis. J. Thorac. Cardiovasc. Surg., 81 (2): 212-218, 1981.

19. ROBERTS, W. C. - The silver anniversary of cardiac valve replacement. Am. J. Cardiol., 56 (7): 503-506, 1985.

20. RUMISEK, J. D.; BERRY, W. R.; BARRY, M. J.; CLARKE, J. S. - Transseptal control of difficult aortic annulus. Ann. Thorac. Surg., 39 (4): 385-386, 1985.

21. SYMBAS, P. N.; VLASIS, S. E.; ZACHAROPOULOS, L.; LUTZ, J. F. - Acute endocarditis: surgical treatment of aortic regurgitation and aortic-left ventricular discontinuity. J. Thorac. Cardiovasc. Surg., 84 (2): 291-296, 1982.

22. UTLEY, J. R. \& MILLS, J. - Annular erosion and pericarditis: complications of endocarditis of the aortic roots. J. Thorac. Cardiovasc. Surg., 64 (1): 76-81, 1972.

23. VanHOOSER, D. V.; JOHNSON, R, G.; HEIN, R. A.; ELKINS, R. - Sucessful management of aortic valve endocarditis with associated periannular abscess and aneurysm. Ann. Thorac. Surg., 42 (2): 148-151, 1986.

24. WALlace, A. G.; YOUNG Jr., W. G.; OSTERHOUT, S. - Treatment of acute bacterial endocarditis by valve excision and replacement Circulation, 31 (3): 450-433, 1965.

\section{Discussão}

\section{DR. ANTOONIO PRADO FORTUNA \\ Campinas, $S P$}

Desejamos cumprimentar os autores do presente trabalho, pela elegante apresentação e con- tribuição que trazem ao tratamento cirúrgico da endocardite infecciosa quando há erosão ou disruptura da membrana aórtico-mitral. Iniciamente, gostaríamos de fazer alguns comentários de ordem anatômica: (slide 1) A membrana aórtico-mitral compreende, em seu conjunto, o anel aórtico; o trígono fibroso esquerdo; o trígono fibroso direito com o tendão de Todaro; o trígono intervalvar e as cúspides da valva atrioventricular esquerda. A endocardite infecciosa pode comprometer toda a membrana aórtico-mitral, mas, na maioria das vezes, fica limitada a região das cúspides aórticas não coronariana, coronariana direita e esquerdas aquém dos óstios coronários (slide 2). Nos 2 últimos casos apresentados pelos autores, o processo se estendeu ao trígono intervalvar, o que ocasionou a descontinuidade aórtico-mitral (slide 3). A técnica proposta compreendeu o "levantamento da valva mitral", por meio de pontos separados, fechando com um retalho duplo de pericárdio bovino a área abcedada, sendo a inserção da prótese apoiada nesse mesmo retalho. Nós tivemos, em uma oportunidade, situação semelhante, na qual fechamos, em primeiro lugar, a área abcedada, com pontos separados ancorados em Teflon e, a seguir, fixamos a prótese com outros tantos fios ancorados em Teflon, nessa região, passados de fora para dentro, transfixando a parede aórtica, a uma altura ligeiramente superior ao plano natural de inserção das cúspides aórticas (slide 4). Esta técnica requer a mobilização da reflexão dos átrios sobre a parede aórtica. A técnica proposta pelos autores representa, sem dúvida, uma valiosa contribuição, que, estou certo, todos teremos em mente, da próxima vez em que nos depararmos com este tipo de complicação.

\section{DR. ARNONI}

(Encerrando)

Agradeço as consideraçōes do Dr. Fortuna e, como conclusão, gostaria de dizer que acreditamos que a técnica que ora apresentamos nos parece uma boa opção para o tratamento cirúrgico da descontinuidade ventrículo esquerdo-aorta, nos casos de endocardite, e vamos acompanhar a evolução dos pacientes operados, para termos uma definição de como o retalho empregado se comportará com o passar dos anos. Obrigado. 